\title{
The effects of dual-task training on balance and gross motor function in children with spastic diplegia
}

\author{
Na-Yun Lee ${ }^{1,2}$, Eun-Jung Lee ${ }^{1,2}$, Hae-Yeon Kwon ${ }^{3, *}$ \\ 'Ulsan Community Rehabilitation Center, Ulsan, Korea \\ ${ }^{2}$ Department of Biomedical Health Science, Graduate School, Dong-Eui University, Busan, Korea \\ ${ }^{3}$ Department of Physical Therapy, College of Nursing and Healthcare Science, Dong-Eui University, Busan, Korea
}

The purpose of this study was to investigate changes in dynamic balance and gross motion function when dual-task training was performed on an unstable support surface by children with spastic diplegia. The subjects of this study were 14 children (experimental group $n=7$, control group $n=7$ ) who were medical diagnosed with spastic diplegia. Both groups were administered treatment for 30 min, 2 times a week for 8 weeks, with the experimental group performing dual-task exercise in which cognitive tasks related to daily living were performed while maintaining balance on an unstable surface, and the control group being administered neuro-developmental treatment. Balance and gross motor function Assessments were conducted before intervention and after 8 weeks of intervention. Wilcoxon signed-rank test was performed to analyze changes in balance, gross motor function in the group, and the
Mann-Whitney test was conducted to compare the differences between the two groups before and after intervention. The results showed that there was a statistically significant difference in both groups when balance in a sitting position and gross motor function $(P<0.05)$. There was a statistically significant difference between the two groups in balance and gross motor function assessment $(P<0.05)$. Based on the results of this study, it was confirmed that dual-task training improves balance, gross motor function in children with spastic diplegia. Therefore, dual-task training may be considered as an effective method of intervention method in the functional aspect of children with spastic diplegia.

Keywords: Spastic diplegia, Dual-task training, Balance, Gross motor

\section{INTRODUCTION}

Cerebral palsy is a nonprogressive impairment or lesion occurring in immature brains and is a neurodevelopmental disorder that causes permanent impairment to movement and postural development and brings about activity limitation (Rosenbaum et al., 2007). Cerebral palsy mostly causes problems such as abnormal muscular tone as in spasticity, muscular weakness, coordination disorder, and ataxia (Maruishi et al., 2001), and also restricts complex movement such as loss of selective movement and impairment of coordination and balance (Papavasiliou, 2009).

Such impairments of the postural control and balancing abilities of children with cerebral palsy limit the activities of daily living depending on the body functionality (Surveillance of Cerebral Palsy in Europe, 2002) and lead to activity constraints and social participation restrictions (Himmelmann et al., 2006). Accordingly, for intervention of children with cerebral palsy, not only should the improvement in the level of bodily impairment be taken into account, but also enhancement of the functional level and activity participation should be considered.

Various intervention methods such as progressive resistance exercises, strength exercises, and so on for the improvement of the body functionality of children with cerebral palsy have been reported (Bania et al., 2016; Stubbs and Diong, 2016). Wulf et al. (2009) has reported a positive effect on balance and postural control ability when external focus exercises are completed using a tool such as a balance pad. However, interventions for which only the body functions are taken into account have limitations in performing functional tasks in daily living, and for this reason, studies have been announced that the regard physical abilities of indi-
${ }^{*}$ Corresponding author: Hae-Yeon Kwon (iD https://orcid.org/0000-0002-8345-6315 Department of Physical Therapy, College of Nursing and Healthcare Science, Dong-Eui University, 176 Eomgwangno, Busanjin-gu, Busan 47340, Korea Email: sunlotus75@deu.ac.kr

Received: January 1, 2021 / Accepted: January 31, 2021
This is an Open Access article distributed under the terms of the Creative Commons Attribution Non-Commercial License (https://creativecommons.org/licenses/by-nc/4.0/) which permits unrestricted non-commercial use, distribution, and reproduction in any medium, provided the original work is properly cited. 
viduals and connected activities of complex task performance in daily living as important perspectives (Brauer et al., 2002).

Dual-task training is an intervention of performing two or more complex tasks differently in nature that frequently take place in daily life, and it is a method of training wherein a different task is additionally performed when a basic task is performed or two or more tasks are performed concurrently (Kim et al., 2014). When dual-task training is undertaken by combining cognitive and motor tasks, a cognitive-motor interference effect appears (Plummer-D'Amato et al., 2008).

Significantly enhanced postural stability in motor-cognitive training group as compared to motor or cognitive alone training group (An et al., 2014). This dual-task training can be applied to the elderly to perform balance control, sensory and cognitive tasks, and reduce the risk of falls. Accordingly, dual-task training, which includes a cognitive task and a postural \& gait-oriented task, can improve the functional movements of patients with neurological impairment (Kim et al., 2014).

As dual-task training can elicit behavioral modalities by encouraging two motor tasks to be performed simultaneously (Nashner and Peters, 1990), it has greater significance if the trainee has a cognitive disorder and motor disturbance, such as cerebral palsy. However, there is still insufficient research on applying dual-task training in children with cerebral palsy.

For this reason, the present study intends to look into the effect of dual-task training on the gross motor functionality and balance of the children with cerebral palsy by conducting dual-task training where training of balancing on an unstable support surface and performance of the tasks related to the activities of daily living take place at the same time to the children with spastic diplegia cerebral palsy.

\section{MATERIALS AND METHODS}

\section{Participants}

The participants were comprised of 24, 6- to 12-year-old children diagnosed with spastic diplegia cerebral palsy between levels I-III on the Gross Motor Function Classification System (GMFCS). The purpose of the study and process were notified to institutions related to pediatric physical therapy in Ulsan, 14 children who met the criteria of the study subject and who voluntarily expressed their intention to participate were selected. Of the 16 recruited, one with an unsuitable diagnosis and one with Botox experience within 3 months were excluded, and a total of 14 were included.

To be more detailed about the participants, seven children with spastic diplegia cerebral palsy were randomly placed into each the experimental and the control groups, and the study was conducted as a single-blind study which sets the participants without revealing to which group they belong. The objective of the study and the experimental method were explained in detail to the research participants and their guardians (legal representatives), and a consent to the provision of personal information stating that they were participating in the study on a voluntary basis was received from each of them. To protect the rights and safety of the participants of the study and to comply with the Bioethics and Safety Act, an approval was obtained from the Institutional Review Board (IRB) of Dong-Eui University (IRB No. DIRB-201908-HR-R-26).

\section{Measurement method}

The present study is a clinical research study on children with spastic diplegia cerebral palsy and is a two-group, pretest-posttest design for the purpose of investigating the intervention effect of dual-task training. The experimental group underwent dual-test training of performing a cognitive task related to the activities of daily living while maintaining balance on an unstable support surface, and neurodevelopmental treatment was applied to the control group. The intervention was applied to both groups for $30 \mathrm{~min}$ in each session, two sessions per week, for a total of 8 weeks. The dual-task training program was constructed with reference to the frequency and application time of the intervention program of Liu et al. (2017) and Park and Lee (2019). Balance ability and the gross motor functions were measured before and after the intervention.

The content of the dual-task training of the present study was organized with task performance of controlling balance on an unstable support surface accompanied concurrently by diverse cognitive activities such as play activities. The contents of the tasks to be performed were organized with programs that allow to take into account the activities of children's daily living and also can motivate the children. For the balance exercise, the support surface was narrowed and the gravitational center was elevated by allowing the participants to shift from a seated posture to a standing posture, and the support surface was further developed from a solid one to a dynamic one. A Swiss ball with a diameter of $45 \mathrm{~cm}$, which is the appropriate height that allows a child to maintain a seated posture, an Airex balance pad with dimensions of $47 \mathrm{~cm} \times$ $40 \times 6 \mathrm{~cm}$, and a dynamic air cushion Deko of Togu with a diameter of $33 \mathrm{~cm}$ were all used for the intervention. Also, for participant's safety and sufficient task performance, the participants were permitted to rest their hands on the table to the extent they did 
Table 1. Dual-task training program

\begin{tabular}{|c|c|c|}
\hline Exercise & Position & Dual-task training program \\
\hline Warming up exercise & Supine & Trunk and lower extremity ROM exercise \\
\hline \multirow[t]{6}{*}{ Main exercise } & Sitting & Base of support: balance cushion, ball \\
\hline & & Program: perform cognition task while maintaining balance (writing, drawing, puzzle etc.) \\
\hline & Bench sitting (half ring P.) & Base of support: balance pad \\
\hline & & Program: perform fine motor activities while maintaining balance (blocks assembly, scissoring, origami etc.) \\
\hline & Standing & Base of support: balance pad, balance cushion \\
\hline & & Program: perform eating while maintaining balance (drinking water, eat a snack etc.) \\
\hline Cool down exercise & Supine & Low extremity stretching \& deep breathing \\
\hline
\end{tabular}

ROM, range of motion.

not lean on the table using their body or arms. Sufficient resting time was provided upon the request of the participants, and the intervention of all the programs was carried out by experienced physical therapists with clinical careers spanning 10 years or longer. The details of the programs are as depicted in Table 1.

\section{BioRescue}

To evaluate balancing ability, a BioRescue Balance Analysis System (RM Ingenierie, Rodez, France) was used. BioRescue is a system which enables the balancing ability of the participants and their levels of bodyweight support to be inspected across diverse postures and the system displays the measurement results on a computer screen both numerically and graphically, providing quick access for interpretation. The static and dynamic balance measurement program embedded in BioRescue was used to monitor the changes in the balancing ability and the distance $(\mathrm{mm})$ and area $\left(\mathrm{mm}^{2}\right)$ the center of pressure moved from the stability limit to the anterior, posterior, and lateral directions of the participant were measured. For measurement, a balance measurement decompression platform embedded with 1,600 sensors was installed on a flat treatment table and each participant was asked to sit down on the decompression platform in the desired posture with the hip joint and knee joints bent at $90^{\circ}$ and the waist stretched. If the participant's legs did not touch the ground in the seated posture, stability was provided by using a footrest. Static balance was measured while the participant maintained a posture of bending the shoulder joints $90^{\circ}$ upon the researcher's signal, and lifting the arms with the elbow joints fully extended for $12 \mathrm{sec}$. Dynamic balance was measured while the participant repeated hand-clapping 8 times with both shoulder joints and elbow joints bent $90^{\circ}$ upon the researcher's signal. The average values of static and dynamic seated balance were calculated by performing the tasks in such a way 3 times in succession. Muscle fatigue was prevented by providing a 5-min resting period between the measurements, and the mea- surements were conducted in a silent environment considering the clinical characteristics of the children with cerebral palsy who typically lack concentration and possess short attention spans.

\section{Gross Motor Function Measure (GMFM)}

To evaluate gross motor function, the Gross Motor Function Measure GMFM-88 was employed. This is a tool used to evaluate the motor functions of children with cerebral palsy between 5 months and 16 years of age. The GMFM is a useful tool that can measure the levels of change in motor development over time by evaluating the levels of gross motor functions of children with cerebral palsy (Damiano and Abel, 1996). This evaluative tool is comprised of 88 items from 5 domains (A: 17 items related to lying down and rolling, B: 20 items related to sitting, C: 14 items related to crawling and kneeling, D: 13 items related to standing, and E: 24 items related to walking/running/jumping). Each item is evaluated on a 4-point scale. Zero points are given when the item is unable to be performed, 1 point is given when the item is able to be started, 2 points are given for partial performance, and 3 points are given for full performance; the total score is calculated by summing each domain score; and each domain score or the total score can be calculated as a percentage (\%). In the present study, we used the total score of the GMFM and the GMFM D and E domain percentage measurement values of the children capable of performing tasks up to independent sitting. The GMFM is a reliable, standardized measurement tool which exhibits inspection item validity at 0.91 (Palisano et al., 2000) and inter-rater reliability at 0.997 (Nordmark et al., 1997).

\section{Data analysis}

The data collected were analyzed using IBM SPSS Statistics ver. 25.0 (IBM Co., Armonk, NY, USA), and the significance level $(\alpha)$ for statistical verification was set at 0.05 . Regarding the general characteristics of the research participants, descriptive statistics 
were calculated, and as to the normality of the measurement variable, a nonparametric test was conducted after checking variabilty through a Sharpiro-Wilk test.

A Wilcoxon signed-rank test was conducted to analyze the changes in the experimental and control groups before and after the intervention, and a Mann-Whitney $U$-test was conducted to compare the difference in the variance between the two groups.

\section{RESULTS}

\section{General characteristics of the research subjects}

Among the total 14 research participants, seven belonged to the experimental group and seven belonged to the control group; seven were males (50\%) and seven were females (50\%); their average age was $9.42 \pm 2.1$ years, average height was $122.78 \pm 14.95 \mathrm{~cm}$, and average weight was $26.17 \pm 7.7 \mathrm{~kg}$, body mass index was $17.06 \pm 2.10 \mathrm{~kg} / \mathrm{m}^{2}$. The result of conducting a homogeneity test for the general characteristics of the experimental group and the

Table 2. General characteristics of subjects

\begin{tabular}{lcccc}
\hline Characteristic & $\begin{array}{c}\text { Experimental } \\
(\mathrm{n}=7)\end{array}$ & $\begin{array}{c}\text { Control } \\
(\mathrm{n}=7)\end{array}$ & $Z$ & $P$-value \\
\hline Gender & & & 0.00 & 1.00 \\
$\quad$ Male & $4(57)$ & $3(43)$ & & \\
$\quad$ Female & $3(43)$ & $4(57)$ & & \\
Age $(\mathrm{yr})$ & $9.42 \pm 2.07$ & $9.42 \pm 2.29$ & -0.19 & 0.84 \\
Height $(\mathrm{cm})$ & $125.14 \pm 12.9$ & $120.42 \pm 17.46$ & -0.64 & 0.52 \\
Weight $(\mathrm{kg})$ & $25.78 \pm 6.19$ & $26.57 \pm 9.48$ & -0.32 & 0.74 \\
Body mass index $\left(\mathrm{kg} / \mathrm{m}^{2}\right)$ & $16.30 \pm 2.19$ & $17.81 \pm 1.84$ & -1.34 & 0.21 \\
Gestational age $($ week $)$ & $35.37 \pm 4.57$ & $35.64 \pm 0.64$ & -0.64 & 0.51 \\
Birth weight $(\mathrm{kg})$ & $2.35 \pm 0.09$ & $2.31 \pm 0.22$ & 0.90 & 0.84 \\
\hline
\end{tabular}

Values are presented as number (\%) or mean \pm standard deviation.

Table 3. Comparison of balance between before and after intervention

\begin{tabular}{|c|c|c|c|c|c|}
\hline Variable & Group & Pre & Post & Z & $P$-value \\
\hline \multicolumn{6}{|l|}{ Static balance } \\
\hline \multirow{2}{*}{$\begin{array}{l}\text { Surface area } \\
\text { ellipse }\left(\mathrm{mm}^{2}\right)\end{array}$} & Experimental & $116.85 \pm 66.34$ & $7.42 \pm 3.64$ & -2.36 & $0.01^{*}$ \\
\hline & Control & $96.57 \pm 65.91$ & $76.57 \pm 64.76$ & -2.37 & $0.01^{*}$ \\
\hline \multirow[t]{2}{*}{ Length (cm) } & Experimental & $37.35 \pm 19.20$ & $5.41 \pm 3.32$ & -2.36 & $0.01^{*}$ \\
\hline & Control & $23.58 \pm 11.03$ & $18.38 \pm 10.47$ & -2.36 & $0.01^{*}$ \\
\hline \multicolumn{6}{|l|}{ Dynamic balance } \\
\hline \multirow{2}{*}{$\begin{array}{l}\text { Surface area } \\
\quad \text { ellipse }\left(\mathrm{mm}^{2}\right)\end{array}$} & Experimental & $99.42 \pm 44.85$ & $25.0 \pm 16.51$ & -2.36 & $0.02^{*}$ \\
\hline & Control & $93.14 \pm 80.22$ & $71.71 \pm 75.37$ & -2.36 & $0.02^{*}$ \\
\hline \multirow[t]{2}{*}{ Length (cm) } & Experimental & $18.30 \pm 6.24$ & $5.35 \pm 2.66$ & -2.36 & $0.02^{*}$ \\
\hline & Control & $20.55 \pm 11.48$ & $14.70 \pm 8.87$ & -2.37 & $0.02^{*}$ \\
\hline
\end{tabular}

Values are presented as mean \pm standard deviation.

${ }^{*} P<0.05$. control group indicated that the two groups did not exhibit any significant differences. The details of the general characteristics are as shown in Table 2.

\section{Balance}

As to the area and distance of the pressure center movement during static seated balance before and after intervention, both the experimental group and the control group showed a statically significant difference $(P<0.05)$ (Table 3$)$, and regarding the variance of static seated balance before and after the intervention, there was a significant difference between the two groups $(P<0.05)$ (Table 4 ).

As to the area and distance of the pressure center movement during dynamic seated balance before and after intervention, both the experimental group and the control group showed a statically significant difference $(P<0.05)$ (Table 3$)$, and regarding the variance of static seated balance before and after the intervention, there was a significant difference between the two groups $(P<0.05)$ (Table 4).

\section{Gross Motor Function}

The experimental group and the control group did not show any significant differences in the GMFM D standing domain as a result of intervention, and the experimental group showed a signifi-

Table 4. Difference of balance change between the two groups

\begin{tabular}{lcccc}
\hline Variable & Experimental & Control & $Z$ & $P$-value \\
\hline Static balance & & & & \\
$\quad$ Surface area ellipse $\left(\mathrm{mm}^{2}\right)$ & $-109.34 \pm 63.37$ & $-20.00 \pm 8.56$ & -2.75 & $0.00^{*}$ \\
$\quad$ Length $(\mathrm{cm})$ & $-31.94 \pm 20.02$ & $-5.20 \pm 3.02$ & -2.74 & $0.00^{*}$ \\
Dynamic balance & & & & \\
$\quad$ Surface area ellipse $\left(\mathrm{mm}^{2}\right)$ & $-74.42 \pm 38.27$ & $-21.42 \pm 12.58$ & -3.13 & $0.00^{*}$ \\
Length $(\mathrm{cm})$ & $-12.94 \pm 5.12$ & $-5.85 \pm 3.82$ & -2.49 & $0.01^{*}$ \\
\hline
\end{tabular}

Values are presented as mean \pm standard deviation.

${ }^{*} P<0.05$.

Table 5. Comparison of GMFM between before and after intervention

\begin{tabular}{llcccl}
\hline Variable & \multicolumn{1}{c}{ Group } & Pre & Post & $Z$ & $P$-value \\
\hline GMFM D (standing) & Experimental & $78.00 \pm 28.08$ & $82.57 \pm 31.07$ & -1.75 & 0.08 \\
& Control & $68.71 \pm 39.33$ & $69.57 \pm 39.86$ & -1.60 & 0.10 \\
GMFM E (walking, & Experimental & $74.71 \pm 29.95$ & $79.28 \pm 31.11$ & -2.37 & $0.01 *$ \\
running, jumping) & Control & $62.28 \pm 36.61$ & $64.14 \pm 37.83$ & -1.82 & 0.06 \\
GMFM total & Experimental & $88.42 \pm 15.16$ & $90.71 \pm 15.14$ & -2.41 & $0.01 *$ \\
& Control & $81.85 \pm 21.53$ & $82.57 \pm 21.67$ & -2.23 & $0.02^{*}$
\end{tabular}

Values are presented as mean \pm standard deviation

GMFM, gross motor function measure.

${ }^{*} P<0.05$. 
Table 6. Difference of GMFM change between the two groups

\begin{tabular}{lcccc}
\hline Variable & Experimental & Control & $Z$ & $P$-value \\
\hline GMFM D (standing) & $5.42 \pm 5.15$ & $0.85 \pm 1.21$ & -1.90 & 0.05 \\
GMFM E (walking, running, jumping) & $4.57 \pm 4.07$ & $0.28 \pm 0.48$ & -2.97 & $0.00^{*}$ \\
GMFM total & $2.28 \pm 0.95$ & $0.57 \pm 0.53$ & -2.77 & $0.00^{*}$
\end{tabular}

Values are presented as mean \pm standard deviation.

GMFM, gross motor function measure.

${ }^{*} P<0.05$.

cant difference in the GMFM E walking/running/jumping domain after the intervention. Both the experimental and control groups showed statistically significant differences in the average of the overall GMFM as a result of the intervention $(P<0.05)$ (Table 5).

There was no significant difference in the variance of GMFM D standing domain before and after the intervention between the two groups, and as to the variances in the total values of the GMFM E walking/running/jumping domain and gross motor functions, there were statistically significant differences between the two groups $(P<0.05)$ (Table 6).

\section{DISCUSSION}

The present study intended to look into the effects of dual-task training when dual-task training involving cognitive task performance related to the activities of daily living while maintaining balance on diverse support surfaces was applied to children with spastic diplegia cerebral palsy. Balance is an essential element in maintaining stability in static and dynamic activities as it regulates the movement of the body through postural control (Wikstrom et al., 2005). Therefore, exercise on an unstable support surface stimulates tactile sensation, vestibular sensations, proprioceptive sensations, etc. to induce posture and balance reactions, thereby promoting dynamic stability (Sekendiz et al., 2010).

Araújo et al. (2020) systematic review of the dual-task effect, including seven studies of 194 participants, found that combining balance training interventions with other active interventions could increase the effect on postural control. It can be said to be similar to the results of this study, which confirmed the improvement of static and dynamic balance through the performance of the task. In addition, Elhinidi et al. (2016) reported the effect of postural stability through dual-task training for hemiplegic children 3 times a week for 6 weeks. And several studies (Blanchard et al., 2005; Laufer et al., 2008) have reported the effect of dualtask training, which is a combination of physical and cognitive task performance, on postural shaking of spastic cerebral palsy, which is consistent with the results of this study.
As a result of a system review of 42 studies on dual-task training to improve postural stability in patients with difficulty in balance, $87.5 \%$ reported significant effectiveness of dual-task training, Especially, it showed improvement in the elderly and chronic stroke patients (Ghai et al., 2017). Also, it was reported (Behm and Colado, 2012, 2013) that balance training on an unstable support surface increased trunk muscle activation by up to $47.3 \%$ along with the effect size of 2.5 , and it can be said that the trunk muscles of this study's experimental group were activated and both the balancing ability and gross motor function were improved through balance training on diverse support surfaces. It is thought that the activity of maintaining balance and correct postural alignment preceded as an activity to adapt to support surfaces and minimization of intervention to enable the participants to improve their balancing ability independently using autonomic reactions, while performing the tasks brought about the positive changes in the balancing and gross motor functions of the participants.

Research by Ko et al. (2020) reported a positive effect on fine motor function and activities of daily living in children with spastic cerebral palsy through task-oriented group training. In the study by Salem and Godwin (2009), scores of the D (standing) and $\mathrm{E}$ (walking/running/jumping) domain of the GMFM were improved after providing task-oriented training for 5 weeks to children with GMFCS levels I to III cerebral palsy. This further supports the results of the present study in that the total value of the GMFM was significantly improved in the experimental group and the significant improvement was in the $\mathrm{E}$ domain (walking/ running/jumping) among the detailed domains. The participants of the present study were children whose physical abilities were classified as GMFCS level I to III and who were in the development level capable of walking with a walking aid. Accordingly, the motor development of the participants after walking was improved by planning and orienting the tasks to match their physical development and cognitive levels when designing the intervention method, which is believed to have had a positive effect on the significant improvement seen through the GMFM.

Novak et al. (2013) classified the effects of the intervention methods used to treat cerebral palsy in the systematic review study on the basis for intervention of children with cerebral palsy and stated that of the functions related to movement, participation in actual living and the treatment for which the effect was verified to be the highest in the self-help activities were goal-oriented treatment. In the present study, comparison of the GMFM values between the groups before and after the intervention also indicated a significant difference of $1.71 \pm 0.42$. This is a result indicating that 
goal-oriented dual-task training is an intervention method effective in treating children with cerebral palsy as in the preceding studies. Dual-task training where task-oriented training related to the activities of daily living is performed while maintaining balance on an unstable support surface has caused a significant change in the static \& dynamic balance and gross motor function of children with spastic diplegia cerebral palsy. Accordingly, application of dual-task training can be considered to be an effective clinical intervention method in the functional aspects of children with spastic diplegia cerebral palsy.

However, as the number of the research participants of the present study was small, the intervention period was short, and there was no evaluation on the sustainability of the effect after the intervention, there is difficulty in generalizing the lasting effectiveness of dual-task training for children with spastic diplegia cerebral palsy. In addition, the presence or absence of changes in primary impairment levels such as muscle tone and muscle power of cerebral palsy with children in the intervention for the dual task could not be confirmed. Accordingly, diverse studies including studies on the sustainability of the effect of dual-task training that can enhance balance and physical activities of children with spastic diplegia cerebral palsy should be conducted in the future.

\section{CONFLICT OF INTEREST}

No potential conflict of interest relevant to this article was reported.

\section{ACKNOWLEDGMENTS}

The authors received no financial support for this article.

\section{REFERENCES}

An HJ, Kim JI, Kim YR, Lee KB, Kim DJ, Yoo KT, Choi JH. The effect of various dual task training methods with gait on the balance and gait of patients with chronic stroke. J Phys Ther Sci 2014;26:1287-1291.

Araújo PA, Starling JMP, Oliveira VC, Gontijo APB, Mancini MC. Combining balance-training interventions with other active interventions may enhance effects on postural control in children and adolescents with cerebral palsy: a systematic review and meta-analysis. Braz J Phys Ther 2020;24:295-305.

Bania TA, Dodd KJ, Baker RJ, Graham HK, Taylor NF. The effects of progressive resistance training on daily physical activity in young people with cerebral palsy: a randomised controlled trial. Disabil Rehabil

\section{6;38:620-626.}

Behm DG, Colado JC. The effectiveness of resistance training using unstable surfaces and devices for rehabilitation. Int J Sports Phys Ther 2012; 7:226-241.

Behm DG, Colado JC. Instability resistance training across the exercise continum. Sports Health 2013;5:500-503.

Blanchard Y, Carey S, Coffey J. The influence of concurrent cognitive tasks on postural sway in children. Pediatr Phys Ther 2005;17:189-193.

Brauer SG, Woollacott M, Shumway-Cook A. The influence of a concurrent cognitive task on the compensatory stepping response to a perturbation in balance-impaired and healthy elders. Gait Posture 2002; 15:83-93.

Damiano DL, Abel MF. Relation of gait analysis to gross motor function in cerebral palsy. Dev Med Child Neurol 1996;38:389-396.

Elhinidi EI, Ismaeel MM, El-Saeed TM. Effect of dual-task training on postural stability in children with infantile hemiparesis. J Phys Ther Sci 2016;28:875-880.

Ghai S, Ghai I, Effenberg AO. Effects of dual tasks and dual-task training on postural stability: a systematic review and meta-analysis. Clin Interv Aging 2017;12:557-577.

Himmelmann K, Beckung E, Hagberg G, Uvebrant P. Gross and fine motor function and accompanying impairments in cerebral palsy. Dev Med Child Neurol 2006;48:417-423.

Kim GY, Han MR, Lee HG. Effect of dual-task rehabilitative training on cognitive and motor function of stroke patients. J Phys Ther Sci 2014; 26:1-6.

Ko EJ, Sung IY, Moon HJ, Yuk JS, Kim HS, Lee NH. Effect of group-taskoriented training on gross and fine motor function, and activities of daily living in children with spastic cerebral palsy. Phys Occup Ther Pediatr 2020;40:18-30.

Laufer Y, Ashkenazi T, Josman N. The effects of a concurrent cognitive task on the postural control of young children with and without developmental coordination disorder. Gait Posture 2008;27:347-351.

Liu YC, Yang YR, Tsai YA, Wang RY. Cognitive and motor dual task gait training improve dual task gait performance after stroke - a randomized controlled pilot trial. Sci Rep 2017;7:4070.

Maruishi M, Mano Y, Sasaki T, Shinmyo N, Sato H, Ogawa T. Cerebral palsy in adults: independent effects of muscle strength and muscle tone. Arch Phs Med Rehabil 2001;82:637-641.

Nashner LM, Peters JF. Dynamic posturography in the diagnosis and management of dizziness and balance disorders. Neurol Clin 1990;8:331349.

Nordmark E, Hagglund G, Jarmlo GB. Reliability of the gross motor function measure in cerebral palsy. Scand J Rehabil Med 1997;29:25-28.

Novak I, McIntyre S, Morgan C, Campbell L, Dark L, Morton N, Stumbles 
E, Wilson SA, Goldsmith S. A systematic review of interventions for children with cerebral palsy: state of the evidence. Dev Med Child Neurol 2013;55: 885-910.

Palisano RJ, Hanna SE, Rosenbaum PL, Ruseell DJ, Walter SD, Wood EP, Raina PS, Galuppi BE. Validation of a model of gross motor function for children with cerebral palsy. Phys Ther 2000;80:974-985.

Papavasiliou AS. Management of motor problems in cerebral palsy: a critical update for the clinician. Eur J Paediatr Neurol 2009;13:387-396.

Park MO, Lee SH. Effect of a dual-task program with different cognitive tasks applied to stroke patients: a pilot randomized controlled trial. NeuroRehabilitation 2019;44:239-249.

Plummer-D'Amato P, Altmann LJ, Saracino D, Fox E, Behrman AL, Marsiske M. Interactions between cognitive tasks and gait after stroke: a dual task study. Gait Posture 2008;27:683-688.

Rosenbaum P, Paneth N, Leviton A, Goldstein M, Bax M, Damiano D, Dan B, Jacobsson B. A report: the definition and classification of cerebral palsy April 2006. Dev Med Child Neurol 2007;109:8-14.

Salem Y, Godwin EM. Effects of task-oriented training on mobility func- tion in children with cerebral palsy. NeuroRehabilitation 2009;24:307313.

Sekendiz B, Cuğ M, Korkusuz F. Effects of Swiss ball core strength training on strength, endurance, flexibility, and balance in sedentary women. J Strength Cond Res 2010;24:3032-3040.

Stubbs PW, Diong, J. The effect of strengthening interventions on strength and physical performance in people with cerebral palsy (PEDro synthesis). Br J Sports Med 2016;50:189-190.

Surveillance of Cerebral Palsy in Europe. Prevalance and characteristics of children with cerebral palsy in Europe. Dev Med Child Neurol 2002;44:633-640.

Wikstrom EA, Tillman MD, Smith AN, Borsa PA. A new force-plate technology measure of dynamic postural stability: the dynamic postural stability index. J Athl Train 2005;40:305-309.

Wulf G, Landers M, Lewthwaite R, Töllner T. External focus instructions reduce postural instability in individuals with Parkinson disease. Phys Ther 2009;89:162-168. 